\title{
Flavonoids and darkness lower PCD in senescing Vitis vinifera suspension cell cultures
}

\author{
Alberto Bertolini, Elisa Petrussa, Sonia Patui, Marco Zancani, Carlo Peresson, Valentino Casolo, Angelo Vianello \\ and Enrico Braidot ${ }^{*}$ (i)
}

\begin{abstract}
Background: Senescence is a key developmental process occurring during the life cycle of plants that can be induced also by environmental conditions, such as starvation and/or darkness. During senescence, strict control of genes regulates ordered degradation and dismantling events, the most remarkable of which are genetically programmed cell death (PCD) and, in most cases, an upregulation of flavonoid biosynthesis in the presence of light. Flavonoids are secondary metabolites that play multiple essential roles in development, reproduction and defence of plants, partly due to their well-known antioxidant properties, which could affect also the same cell death machinery. To understand further the effect of endogenously-produced flavonoids and their interplay with different environment (light or dark) conditions, two portions (red and green) of a senescing grapevine callus were used to obtain suspension cell cultures. Red Suspension cell Cultures (RSC) and Green Suspension cell Cultures (GSC) were finally grown under either dark or light conditions for 6 days.
\end{abstract}

Results: Darkness enhanced cell death (mainly necrosis) in suspension cell culture, when compared to those grown under light condition. Furthermore, RSC with high flavonoid content showed a higher viability compared to GSC and were more protected toward PCD, in accordance to their high content in flavonoids, which might quench ROS, thus limiting the relative signalling cascade. Conversely, PCD was mainly occurring in GSC and further increased by light, as it was shown by cytochrome $c$ release and TUNEL assays.

Conclusions: Endogenous flavonoids were shown to be good candidates for exploiting an efficient protection against oxidative stress and PCD induction. Light seemed to be an important environmental factor able to induce PCD, especially in GSC, which lacking of flavonoids were not capable of preventing oxidative damage and signalling leading to senescence.

Keywords: Cell cultures, Flavonoids, PCD, Senescence, Vitis vinifera

\section{Background}

Plant senescence is a multifactorial process involving several signalling pathways, which require an active regulation by nuclear genes. The presence of redundant processes confers resilience, which is ensured by the activation of a vicarious pathway when the main process fails to reach completion. In addition, the simultaneous presence of parallel pathways allows modulating and strengthening senescence induction. Three

\footnotetext{
* Correspondence: enrico.braidot@uniud.it

Department of Agricultural, Food, Animal and Environmental Sciences, University of Udine, via delle Scienze, 91, 33100 Udine, Italy
}

main senescence inducers have been recognized, such as carbon starvation, darkness and developmental process [1]. Starvation and darkness substantially consist in cell sugar depletion, while development is a process more finely regulated by gene activation. Dark treatment, if applied in detached leaves, would not be considered the most appropriate experimental model to mimic the natural process. Hence, other stress phenomena, such as water stress on individual leaves, overlap to the cascade of events leading to cell death [2]. In the case of grape cell cultures, here presented, it is possible to study the effect of darkness avoiding 
the overlapping of the other stress phenomena mentioned above.

Several hundred genes are expressed during leaf senescence in Arabidopsis, some of which are related to flavonoid biosynthesis [3]. On the other hand, those related to flavonoid synthesis could be differentially regulated, depending on the type of senescence, since in cell cultures the developmental- and starvationinduced senescence differs from that induced by darkness [1].

According to this scheme, the hormonal elicitation of plant senescence is specific. Developmental senescence implies the participation of ethylene, methyl jasmonate and salicylate, while the latter is not involved in darkness- and starvation-induced senescence [1]. In particular, by modulating genes, hormones play a crucial role, similarly to what has been found in programmed cell death (PCD) [4]. In this case, the involvement of many signalling molecules and a large interplay network have been described.

In Arabidopsis suspension cell cultures, heat-induced cell death and senescence share many similar features of PCD [5], whose involvement has already been described in processes such as hypersensitive reaction (HR), aerenchyma differentiation under hypoxic conditions and xylem differentiation [6]. PCD exhibits peculiar characteristics (i.e. DNA laddering and vacuole fragmentation) that are also found in the late phase of senescence [1].

Flavonoids are widespread secondary metabolites in plants. The most abundant classes are the flavan-3-ols, anthocyanins and flavonols, whereas the most common class of phenolic non-flavonoid antioxidants includes the hydroxycinnamates [7]. Their composition and quality depend on plant growth conditions, geographic location and cultivars.

Anthocyanins and colourless flavonoids are mainly localized in different specialized sub-cellular compartments, such as vacuole and cell wall, where they can reach a higher concentration when compared to the animal counterparts. It is therefore interesting to verify whether their effect might be pro-apoptotic, as it generally occurs in animal cells [8], or anti-apoptotic. Anthocyanin accumulation in pigmented cells can prevent developmental- or oxidative stress-mediated PCD-like death, as seen in lace plant (Aponogeton madagascariensis) and Arabidopsis cell lines, respectively [9-11]. Pigmented cells, in comparison to non-pigmented ones, are more protected by flavonoids against the oxidative stress [12]. This suggests that these metabolites possess an anti-apoptotic effect, related to a decrease in reactive oxygen species (ROS) production and propagation. Hence, the anti-apoptotic mechanism proposed for flavonoids in plants could be generally rationalised as an anti-oxidant activity. This effect could also explain the delay of ripening and senescence, reported in anthocyanin-enriched varieties of tomatoes [13].

Anthocyanins and colourless flavonoids also perform a key role in human health, acting as antioxidants by preventing some ROS-associated diseases, such as cancer $[14,15]$, or acting as tumour-inhibiting natural molecules in cancer cell lines [16-19].

Grapevine (Vitis vinifera L.) is a widespread cultivated plant rich in polyphenols (mainly flavonoids and stilbenes), which are present in most tissues. They are synthesized and accumulated during the plant cycle and play several roles in response to biotic and abiotic stress. Grapevine flavonoids, including anthocyanins, are powerful antioxidants, protecting leaves and berries against UV photo-oxidative damage, but could also act as seed dispersers or pollinator recruiters $[20,21]$. In grapevine cell cultures, treatment with cellulase elicits HR-like responses, causing localised cell death, browning and inducing phenolic metabolism [22]. In accordance, Repka and co-authors showed that the HR, elicited by methyl jasmonate in grapevine, induces the activation of genes related to defence, PCD and phenylpropanoid biosynthesis [23, 24]. Nevertheless, in all these studies on plant elicitor- or apoptosis activatorinduction of PCD, it is difficult to distinguish whether flavonoid accumulation in the cell is among the consequences of HR, or the main cause of cell death through induction of a pro-apoptotic effect.

In the present work, starving solid grapevine cell cultures grown under light were obtained by extending their growth largely beyond their proliferation rate plateau. This growth condition induced a pigmented flavonoid production on the outer layers of the cell aggregates, whereas the inner ones, close to nutrients of the medium and protected from an excess of light, remain green and not pigmented. Red and green cells were obtained from this different material and separately sub-cultured in liquid medium under different light regimes (light vs. darkness). These suspension cell cultures represent a simple modelsystem to study the role of endogenous flavonoids in senescence and PCD, avoiding multi-factorial interactions between flavonoid biosynthesis induction and senescence modulation (i.e. osmotic stress, hormonal concentration, nutrient availability, ROS or oxidative stressors). Therefore, this paper focuses on the main effects exerted by dark and light conditions on grapevine senescing suspension cell cultures. In addition, endogenous flavonoids were considered with respect to the role they could play in senescence and/or PCD.

\section{Methods}

Plant material and cell cultures on solid medium

Long-term callus cultures of grapevine (Vitis vinifera L., cv. Limberger), established from young leaf tissues, 
were kindly supplied by V. Repka, Research Institute of Viticulture and Enology, Bratislava, Slovakia. The calli were then maintained on solid media under light, according to Repka et al. [25], with minor modifications. Their maintenance was obtained by sub-culturing them every 14 days for several cycles. For the experiments in suspension cell cultures, this period was extended to 23 days, 1 week longer than the usual growing cycle. At this stage, cells had reached a stationary phase of growth, underwent nutrient starvation and, therefore, had triggered the pathway leading to senescence. The pigmented red cells from 23-day-old cultures, localised on the external cell layers, were selected as a starting inoculum for obtaining Red Suspension cell Cultures (RSC). Similarly, the lightly-green cells in the underneath layers were chosen for obtaining Green Suspension cell Cultures (GSC). RSC and GSC were used for experiments after 3 and 6 days after subculture, in the presence of either darkness or light, respectively.

At day 0, both GSC and RSC were also analysed for the content of soluble hexoses (glucose and fructose, respectively) and for total protein concentration, as general hallmarks of the senescence programme $[26,27]$. Aliquots of $100 \pm 20 \mathrm{mg}$ FW from 3 independent calli were ground into frozen powder under liquid nitrogen. For protein analysis, the powder was resuspended in $0.5 \mathrm{ml}$ of $50 \mathrm{mM}$ Tris- $\mathrm{HCl}(\mathrm{pH} 7.5)$ and protein measured by Bradford method [28] and expressed as $\mathrm{mg} \mathrm{g}^{-1} \mathrm{FW}$.

For sugar analysis, the powder was suspended in $1 \mathrm{ml}$ of $50 \mathrm{mM}$ Tris- $\mathrm{HCl}, 0.05 \%$ Triton X-100, boiled at $100{ }^{\circ} \mathrm{C}$ for $5 \mathrm{~min}$ and centrifuged by a Mikro 120 Hettich centrifuge. The supernatant was used for the standard enzymatic assay of glucose and fructose, measured by a Perkin-Elmer fluorimeter at the wavelengths of 329 and $460 \mathrm{~nm}$ for excitation and emission, respectively [29]. Hexose content was expressed as $\mu \mathrm{mol} \mathrm{g} \mathrm{g}^{-1} \mathrm{FW}$.

\section{Suspension cell cultures}

For all experiments, $4 \mathrm{~g}$ (fresh weight, FW) of either GSC or RSC were transferred into $120 \mathrm{ml}$ of fresh liquid medium contained in $250 \mathrm{~cm}^{3}$ Erlenmeyer flask. The flasks were maintained in an INNOVA 2300 platform shaker, rotating at $110 \mathrm{rpm}$ and kept at $27 \pm 1{ }^{\circ} \mathrm{C}$. Finally, GSC and RSC were grown for 6 days either under light (12 h light period) or in dark conditions, respectively.

\section{Determination of growth rate}

Aiming at estimating the growth rate of cell cultures grown on solid medium, $3 \mathrm{~g}$ FW of callus pieces was initially transferred to a fresh solid medium. Calli were picked up and re-weighed after 3, 6, 9, 12, 15, 18, 21 and 23 days of proliferation.

\section{Extraction of flavonoids}

Grapevine GSC and RSC were grown under light conditions, harvested at day 0 and 6 , frozen in liquid nitrogen and ground to a fine powder. Then, $0.5 \mathrm{~g}$ (FW) of frozen powder was incubated overnight with $1 \mathrm{ml}$ of $15 \%(v / v)$ $\mathrm{HCl}$ in methanol to extract flavonoids. The alcoholic extracts (suspensions) were then centrifuged $10 \mathrm{~min}$ at $12,000 \mathrm{~g}$ in a Mikro 120 Hettich centrifuge. The supernatants were recovered, dried under $\mathrm{N}_{2}$ flow and finally dissolved in $200 \mu \mathrm{l}$ of mobile phase ( $85 \%$ methanol and $15 \%$ bidistilled water).

\section{RP-HPLC analysis of flavonoids}

HPLC separation and quantification were performed with $0.5 \%(v / v)$ acetic acid, $\mathrm{pH} 2.5$ (eluent A) and methanol (eluent B) at a flow rate of $0.5 \mathrm{ml} \mathrm{min}^{-1}$. RPHPLC was performed on a Zorbax Eclipse extra dense bonding-C18 column $(5 \mu \mathrm{m}, 4.6 \times 150 \mathrm{~mm}$, Agilent 1200 series Instrument), equipped with a binary pump delivery system, coupled to a DAD. The binary gradient conditions were: $27-44.5 \%$ B (32 min), then $44.5-$ $67.5 \%$ B (13 min), 67.5-100 \% B (2 min), isocratic $100 \%$ B (3 min). Anthocyanins were monitored at $520 \mathrm{~nm}$ and identified by comparison of their chromatographic profile with the commercial standard malvidin 3-O-glucoside (Extrasynthese, Lyon France).

\section{Mass spectrometry of alcoholic extracts}

Aiming at identifying the main polyphenolic compounds shown by HPLC analysis, alcoholic extracts were obtained as described above from GSC and RSC grown under light for 6 days, and then used for mass spectrometry characterization. Multi-stage Mass Spectrometry $\left(\mathrm{MS}^{\mathrm{n}}\right)$ experiments and liquid chromatography electrospray ionization - mass spectrometry (LC-ESI-MS) analyses were achieved by a Finnigan LXQ Linear Ion Trap, operating in the negative ion mode, coupled with a Dionex UltiMate 3000 RS Pump and equipped with a Dionex UltiMate RS 3000 Autosampler (Thermo Scientific, San Jose, CA, USA). Methanolic standard solutions $\left(200 \mu \mathrm{g} \mathrm{ml}^{-1}\right)$ of gallic acid, quercetin glucoside, quercetin, malvidin-glucoside and kaempferol were infused into the ion source at a flow rate of $10 \mu \mathrm{min}^{-1}$, with the aid of a syringe pump, in order to obtain the corresponding $\mathrm{MS}^{\mathrm{n}}$ spectra (see Supplementary material). Only in the case of cyanidin-glucoside, the identification was performed using data retrieved from an in silico library (http://www.massbank.jp/jsp/Dispatcher.jsp?type=disp\&id= PR020036\&site=1).

The typical source conditions were: transfer line capillary at $275{ }^{\circ} \mathrm{C}$, ion spray voltage at $4.70 \mathrm{kV}$, sheath, auxiliary and sweep gas $\left(\mathrm{N}_{2}\right)$ flow rates at 20,5 and 0 arbitrary units, respectively. Helium was used as the collision damping gas in the ion trap, set at a pressure of 
1 mTorr. ESI-MS ${ }^{\mathrm{n}}$ spectra were obtained by collision induced dissociation (CID) experiments, after isolation of the appropriate precursor ion in the ion trap (isolation width $1.2 \mathrm{~m} / \mathrm{z}$ unit), and subjecting them to the following typical conditions: normalized collision energy between 20 and $30 \%$, selected to preserve a signal of the precursor ion in the order of $5 \%$; activation $Q 0.25$ and activation time $30 \mathrm{~ms}$. The HPLC separations were performed on a Synergi $4 \mu \mathrm{m}$ Hydro-RP 80A column $(250 \mathrm{~mm} \times 2.0 \mathrm{~mm})$ from Phenomenex (Bologna, Italy). The mobile phase consisted of $0.2 \%(v / v)$ formic acid in water (eluent A) and $0.2 \%(v / v)$ formic acid in methanol (eluent $\mathrm{B}$ ), and the linear gradient elution conditions were as follows: $27-44.5 \% \mathrm{~B}$ (32 $\mathrm{min}), 44.5-67.5 \% \mathrm{~B}$ (13 $\mathrm{min}), 67.5-100 \% \mathrm{~B}(2 \mathrm{~min}), 100 \% \mathrm{~B}$ isocratic (19 min), $100-27 \%$ B (3 min), $27 \%$ B isocratic (6 min) at a constant flow rate of $0.1 \mathrm{ml} \mathrm{min}{ }^{-1}$ at $30{ }^{\circ} \mathrm{C}$.

\section{Determination of dead cells}

GSC and RSC were incubated with a solution containing fluorescein diacetate (FDA) to determine cell viability. The FDA working solution was prepared as described by McCabe and Leaver [30]. Cytochemically-stained cells were observed under a LEICA Fluovert fluorescence microscope, using a Nageotte chamber, counting at least 100 aggregate-free cells. The percentage of dead cells was calculated by considering the ratio between the FDA-unstained and the total number of cells.

\section{Reactive oxygen species (ROS) determination}

The generation of ROS was monitored according to the methods of Ledoux et al. and Santos et al. [31, 32], using 2', 7'-dichlorodihydrofluorescein diacetate $\left(\mathrm{H}_{2} \mathrm{DCFDA}\right)$ as a probe. Samples of suspension cell cultures $(2 \mathrm{ml})$, at day 0 , were incubated in 24-well cell culture cluster with $5 \mu \mathrm{M} \mathrm{H}_{2}$ DCFDA. The detection was performed for 105 min using Multilabel Counter (WALLAC, model 1420, Perkin-Elmer) with 5 min-intervals readings, using excitation at $485 \pm 10 \mathrm{~nm}$ and emission at $535 \pm 10 \mathrm{~nm}$. GSC and RSC were also incubated with $1 \mathrm{mM}$ 2,2-azobis(2-methylpropionamide)hydrochloride (ABAP) as free radical initiator. The extent of cell death was evaluated at the beginning and at the end of the assay.

\section{Determination of cellular ATP}

GSC and RSC (approx. $10 \mathrm{~g} \mathrm{FW),} \mathrm{at} \mathrm{different} \mathrm{sampling}$ days $(0,3$ and 6$)$, were first filtered by nylon gauze (100 $\mu \mathrm{m}$ mesh), then frozen with liquid nitrogen and finally ground to a fine powder. Samples $(100 \pm 20 \mathrm{mg}$ FW) were re-suspended in $1 \mathrm{ml}$ of $50 \mathrm{mM}$ Tris- $\mathrm{HCl}$ $(\mathrm{pH} 7.5)$ and $0.05 \%(w / v)$ Triton $\mathrm{X}-100$, and immediately boiled for $2 \mathrm{~min}$. After centrifugation (10 min at $12,000 \mathrm{~g}$ in a Mikro 120 Hettich centrifuge), aliquots of supernatant were used for luminometric assay, as described by Petrussa et al. [29]. ATP calibration curve was performed for each experiment and the sample concentrations were then calculated by interpolation. Apoptotic or necrotic samples at day 0 were prepared as a control by incubating either in ethanol $10 \%(v / v)$ for $24 \mathrm{~h}$ or at $80^{\circ} \mathrm{C}$ for $10 \mathrm{~min}$, respectively.

\section{Detection of cytochrome $c$ release}

Approximately $4 \mathrm{~g}$ FW of GSC or RSC, grown under either light or dark conditions for 6 days, was used for the cytosolic extracts. The material was homogenised with $4 \mathrm{ml}$ of homogenisation buffer $(20 \mathrm{mM}$ HEPES-Tris, pH 7.6; $0.3 \mathrm{M}$ sucrose; $1 \mathrm{mM}$ EDTA; $5 \mathrm{mM}$ DTE; $2 \mathrm{mM}$ PMSF; $1 \mathrm{mM}$ benzamidine and $0.6 \%(w / v)$ PVPP), filtered through a nylon gauze $(100 \mu \mathrm{m}$ mesh $)$ and then centrifuged at $1000 \mathrm{~g}$ for $10 \mathrm{~min}$ at $4{ }^{\circ} \mathrm{C}$ by Mikro 120 Hettich centrifuge, to eliminate debris. The supernatant was centrifuged again at $15,000 \mathrm{~g}$ for $20 \mathrm{~min}$. The obtained supernatant was further ultracentrifuged at $100,000 \mathrm{~g}$ for 40 min by a Beckman L7-55 centrifuge (Ty 70ti rotor) to obtain the final soluble fraction. Soluble proteins were concentrated by $5000 \mathrm{MWCO}$ concentrators VIVASPIN 4 (Sartorius, Göettingen, Germany) at 10,000 $g$ for $30 \mathrm{~min}$ (Mikro 120 Hettich centrifuge). Soluble proteins (ca. $30-40 \mu \mathrm{g})$ were separated by $15 \%(w / v)$ SDSPAGE and electroblotted onto a nitrocellulose membrane. The blots were incubated at $4{ }^{\circ} \mathrm{C}$ overnight with $200 \mu$ of a polyclonal anti-cytochrome $c$ Ab (Agrisera), at 1/1000 dilution. The cross-reaction was finally detected by nitroblue tetrazolium and 5-bromo-4-chloro-3-indolyl phosphate colour development, after incubation with alkaline phosphatase-conjugated anti-rabbit IgG antibody (1/2500 dilution; Sigma, St. Louis, MO, USA). Computer-assisted densitometric analysis of immunoblots was quantified using Quantity One software (Bio-Rad, Hercules, USA).

\section{In situ detection of DNA fragmentation (TUNEL assay)}

Samples of GSC and RSC (1 $\mathrm{ml}$ suspension) were collected at day 0 and 6 and washed three times in phosphate buffered saline (PBS), incubated with fixation solution of $2 \%(v / v)$ paraformaldehyde in PBS for $60 \mathrm{~min}$. Then, samples were treated with permeabilisation solution $(0.1 \%(w / v)$ Triton X-100 in $0.1 \%(w / v)$ sodium citrate) and washed three times with PBS. Samples were labelled with TUNEL reaction mixture (TMR-red in situ cell death detection kit, Roche Diagnostics) in darkness at $37{ }^{\circ} \mathrm{C}$ for $60 \mathrm{~min}$. Negative (without terminal transferase) and positive (with ethanol treatment at day 0 , as described by Hogg et al. [33]) samples were properly included. For nuclear staining, the samples were washed twice by PBS and stained with $1 \mu \mathrm{g} \mathrm{ml}^{-1}$ 4',6-diamidino-2-phenylindole (DAPI) for $15 \mathrm{~min}$. Finally, all samples were examined under a Leitz Fluovert fluorescence microscope, with two 
sets of filters: $360 \mathrm{~nm}$ excitation and $420 \mathrm{~nm}$ emission for DAPI detection; $540 \mathrm{~nm}$ excitation and $620 \mathrm{~nm}$ emission for TUNEL, respectively. The percentage of apoptotic TUNEL-positive nuclei was determined by counting at least 200 nuclei.

\section{Statistical data analysis}

Treatment group means were compared by LSD (Least Significant Difference), according to Fisher's statistical test, and different letters, assigned to means, designate a statistical difference at $P \leq 0.05$. Since cell death and TUNEL positive cells were evaluated as percentage on the total amount of cells, the statistical treatment was performed on such data after their transformation by the formula arcsen $\left(\mathrm{x}^{1 / 2}\right)$. A $t$-test was applied for comparison of protein and sugar content among GSC and RSC calli at day 0 .

\section{Results}

Production of suspension cell cultures from $V$. vinifera (cv. Limberger) and characterization of their flavonoid profile

Grapevine cell cultures were grown under light on a solid medium. After 14 days, these cells reached the optimal growth phase for sub-culturing on solid medium. The growth exhibited a sigmoidal trend that reached a steady-state from 21 to 23 days (Additional file 1: Figure S1). At this stage, accumulation of red pigments on the surface of calli was detected (result not shown). Therefore, red (pigmented) and green (non-pigmented) clusters from the same callus piece were chosen as inoculum for the subculture into liquid medium in order to study the effects of endogenous flavonoid at the onset of senescence. As specified in the Methods section, cell types were obtained from the same callus piece and differed by their relative position (internal/green or external/red). Moreover, green and red cells did not significantly differed in their glucose and fructose concentration (Additional file 2: Table S1), suggesting that both cell types were subjected to a similar degree of senescence induction by hexose signalling. The difference in total protein content, as hallmark of cell degradation, was statistically significant among the cell types $(p=0.01)$. However, the decrease in protein was noticeable in red cells, which showed to be even more protected from PCD than green ones, during subsequent transfer in liquid culture.

The two suspension cell cultures (GSC and RSC) were then maintained in a liquid medium for 6 days under light or darkness. Since the treatments lasted just 6 days, it was considered that after this period dark- and lighttreated cell cultures did not substantially differ for their flavonoid content. For this reason, only in light-grown RSC and GSC, anthocyanin content and composition were analysed by RP-HPLC (Fig. 1, Panel a). The chromatograms show that Limberger cells accumulated mainly cyanidin and malvidin glucosides, as well as their coumaroyl derivatives. In particular, anthocyanin content in GSC was low, with a similar pattern at day 0 (data not shown) and 6 (Panel a, dashed line), respectively, demonstrating that light treatment did not change their flavonoid concentration or composition after 6 days. Conversely, RSC showed an appreciable amount of anthocyanins after 6 days (Panel a, solid line), when compared to GSC. To characterize further the different classes of flavonoids accumulated in both suspension cell cultures at day 6, mass spectrometry (MS) analysis was also performed in alcoholic extracts (Additional file 3: Figure S2). The HPLC chromatograms revealed that, besides to anthocyanins, RSC mainly accumulated gallic

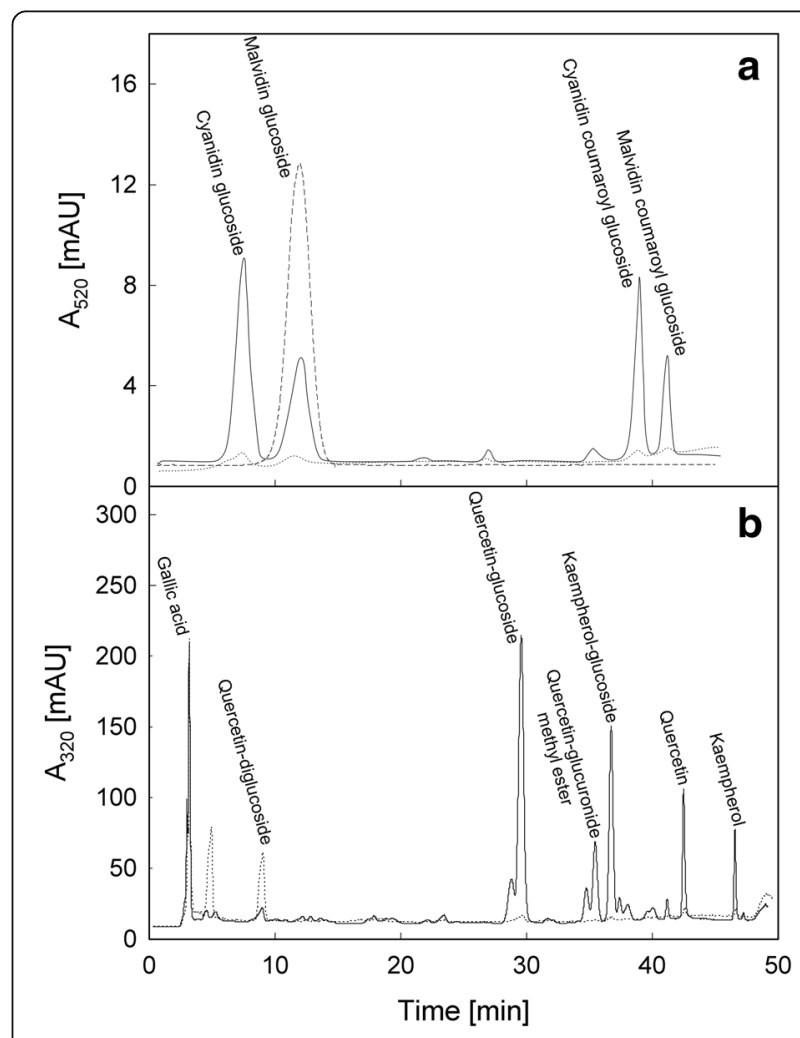

Fig. 1 RP-HPLC analysis of anthocyanins (a) and polyphenolic profile (b) from alcoholic extracts obtained by $V$. vinifera (cv. Limberger) suspension cell cultures. GSC (dotted line) and RSC (solid line) were grown under light conditions for 6 days. Their metabolite content was determined at day 6 . Chromatographic profiles of anthocyanidin glucosides, cyanidin and malvidin, as well as their respective substituted derivatives, are presented. Malvidin glucoside (dashed line) was used as a standard (Panel a). The identification was obtained by mass spectrometry analysis on chromatographic peaks detected at $520 \mathrm{~nm}$. Similar analysis was performed at $320 \mathrm{~nm}$ (Panel b) and the retrieved flavonoids were identified as follows: 1) gallic acid; 2) quercetindiglucoside; 3) quercetin-glucoside; 4) quercetin-glucuronide methyl ester; 5) kaempferol-glucoside; 6) quercetin; 7) kaempferol. Data are representative of three different experiments 
acid, quercetin-glucoside, quercetin, kaempferol-glucoside and kaempferol (Fig. 1, Panel b, solid line). GSC synthesized mainly gallic acid and quercetin-diglucoside (Fig. 1, Panel b, dotted line). The presence of kaempferol-hexose $\left([\mathrm{M}-\mathrm{H}]^{-}\right.$ion at $m / z$ 447), kaempferol-dihexose $\left([\mathrm{M}-\mathrm{H}]^{-}\right.$ ion at $m / z 609)$, quercetin-dihexose $\left([\mathrm{M}-\mathrm{H}]^{-}\right.$ion at $m / z$ $625)$ and quercetin-glucuronide methyl ester $\left([\mathrm{M}-\mathrm{H}]^{-}\right.$ion at $m / z 491$ ) was shown by the mass spectrum of cell extracts obtained by infusion. The identification of these compounds is based on their $\mathrm{MS}^{\mathrm{n}}$ fragmentation behaviour (Additional file 4: Figure S3, Additional file 5: Figure S4, Additional file 6: Figure S5 and Additional file 7: Figure S6). In particular, these compounds show the loss of the hexose $(162 \mathrm{Da})$ or glucuronide methyl ester $(190 \mathrm{Da})$ moieties, generating the corresponding glycoside ions at $m / z 285$ and 301 that, upon further fragmentation, exhibit the typical fragments of kaempferol and quercetin, respectively.

\section{Effects of darkness and endogenous flavonoids on viability of suspension cell cultures}

Light treatment was used as a control to determine the possible effects of darkness and flavonoids on cell viability. Staining with FDA was employed to evaluate the viability of the different cell cultures. Figure 2 (Panel a) shows the morphological features at day 6 of RSC (a) and GSC $(b)$ under visible light, whereas in FDA-stained samples $(c$ and $d$ ), only the alive fluorescent cells were counted. Cell death increased during the whole experimental period, reaching a maximum at day 6 in all samples (Panel b).

This trend was higher in GSC and it was stimulated by darkness, albeit this effect was less evident at day 6. Even in this case, the difference between light- and darktreated cells was lower at day 6 .

\section{Characterization of PCD markers in suspension cell cultures}

Different biochemical and molecular markers of PCD were analysed in order to determine: i) if the observed cell death in the two suspension cell cultures grown under light or dark conditions showed PCD hallmarks; ii) how flavonoids could modulate the PCD manifestation.

TUNEL and DAPI assays were performed on all samples at day 0 and 6 (Fig. 3). Panel a shows the feature of the cells, which were positive to the DAPI and TUNEL reaction. The blue fluorescence-stained nuclei $(b, e)$ were counted as an estimation of the total cell number, while TMR red-fluorescent nuclei $(c, f)$ represented fragmented nuclei in PCD-undergoing cells. These parameters allowed us to estimate the amount of cells undergoing PCD in different treatments at day 0 and 6 (Panel b), because just these samples showed the highest differences in ATP levels between GSC and RSC (see later). PCD was higher in GSC, whereas

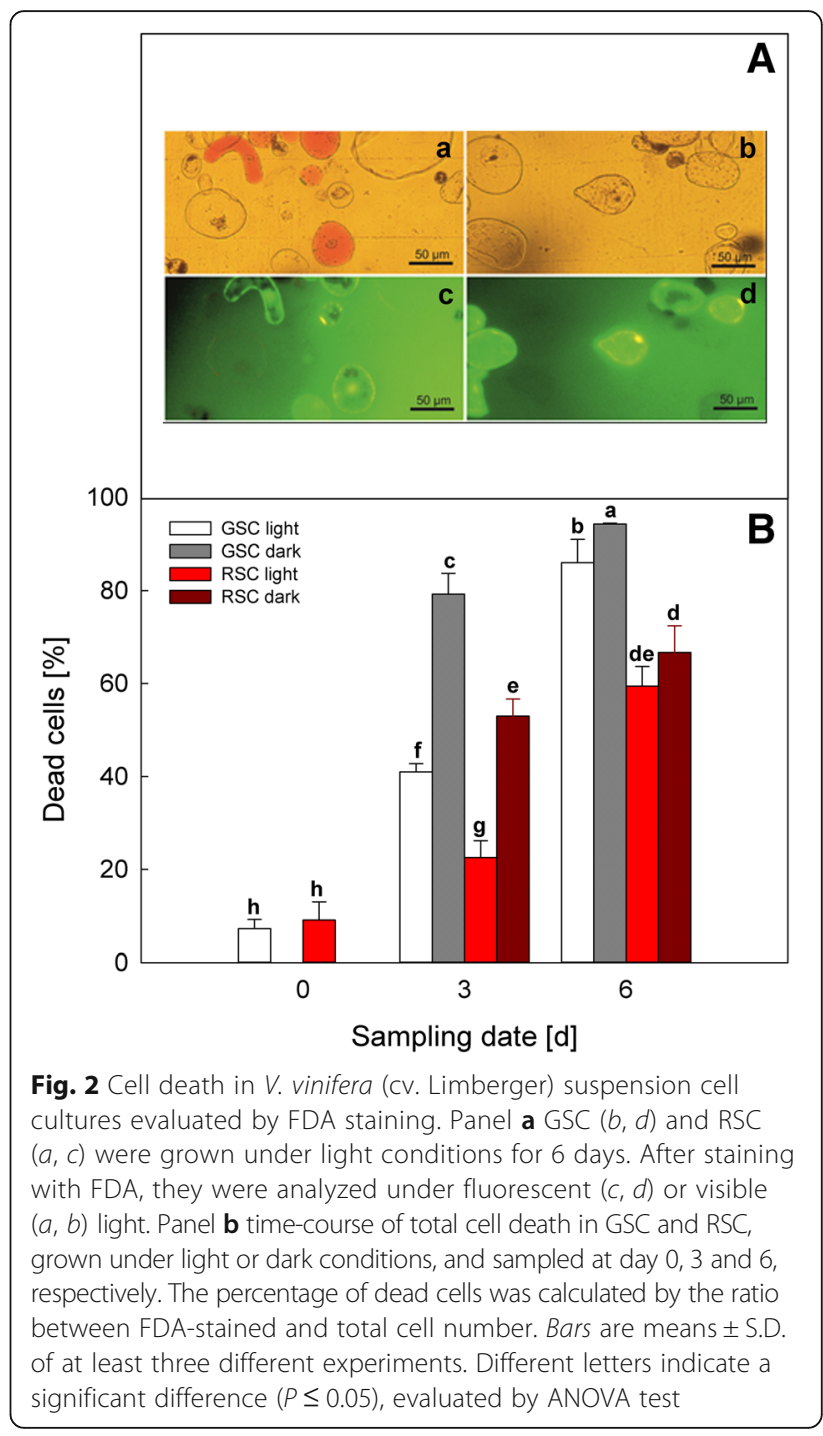

darkness inhibited it. In RSC, flavonoids significantly decreased the amount of TUNEL positive cells and also abolished the effect of darkness, showing that light stimulated PCD only in GSC.

Another hallmark of PCD is represented by cytochrome $c$ release from mitochondria (Fig. 4). This analysis was performed on cytosolic fractions from different treatments at day 6 , in comparison to day 0 , as a control. The densitometric analysis of the antibody cross-reaction showed that cytochrome $c$ release was higher in GSC, in particular under light, than in RSC, in agreement with the results on TUNEL assay. Darkness partially inhibited this release, but had no effect in RSC, in accordance to what was observed in TUNEL analysis.

Since ATP level is known to be crucial for the progress of PCD, its cellular level was assessed at different 


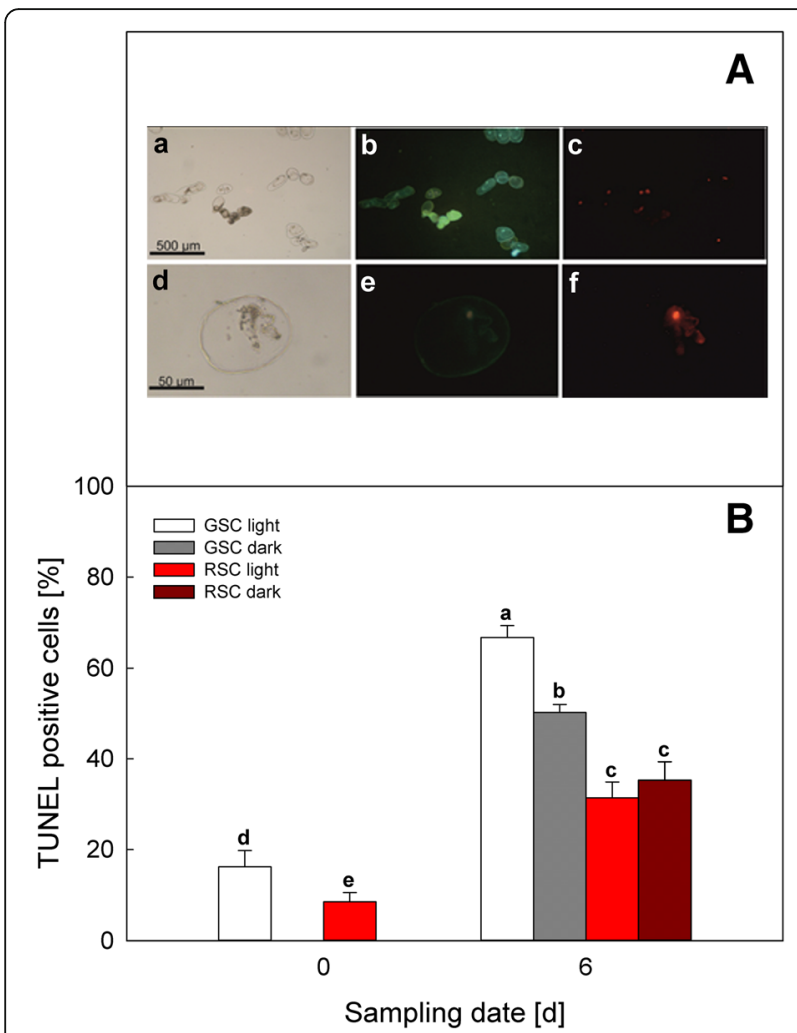

Fig. 3 PCD in V. vinifera (cv. Limberger) suspension cell cultures, evaluated by TUNEL assay. Cells at day 0 were observed under visible light $(a, d)$; nuclei were stained with DAPI $(b, e)$ or TMR-red for TUNEL assay $(c, f)$, and observed under UV light, with low $(b, c)$ and high $(e, f)$ magnification (Panel a). TUNEL assay was performed in GSC and RSC grown under light or dark conditions at day 0 and 6 , to evaluate the percentage of cells undergoing PCD (Panel $\mathbf{b}$ ), counting the cells with red fluorescent-stained nuclei as apoptotic-like dead cells. Bars are means \pm S.D. of at least three different experiments. Different letters indicate significant difference $(P \leq 0.05)$, evaluated by ANOVA test

sampling dates (0, 3 and 6 days, Fig. 5, Panel a). At day 0 , a significant difference between GSC and RSC was observed; in particular, the highest ATP concentration detected in GSC under light could be ascribed to a higher photosynthetic activity. Moreover, ATP content in light-treated GSC increased from day 0 to day 3 and was comparable at day 6 , while in dark conditions GSC underwent a fall in ATP concentration at a level similar to the initial one. In RSC under light treatment ATP level reached its maximum at day 3 and, thereafter, declined at day 6 , while in dark conditions it remained constant at both day 3 and 6 . To evaluate the level of ATP associated to PCD manifestation, a positive control was performed by treating GSC at day 0 with $10 \%$ ethanol ( $83 \pm 0.11 \%$ of PCD, data not shown), in comparison to treatment at $80{ }^{\circ} \mathrm{C}$ for $10 \mathrm{~min}(100 \%$ necrotic cells, data not shown), (Panel b).

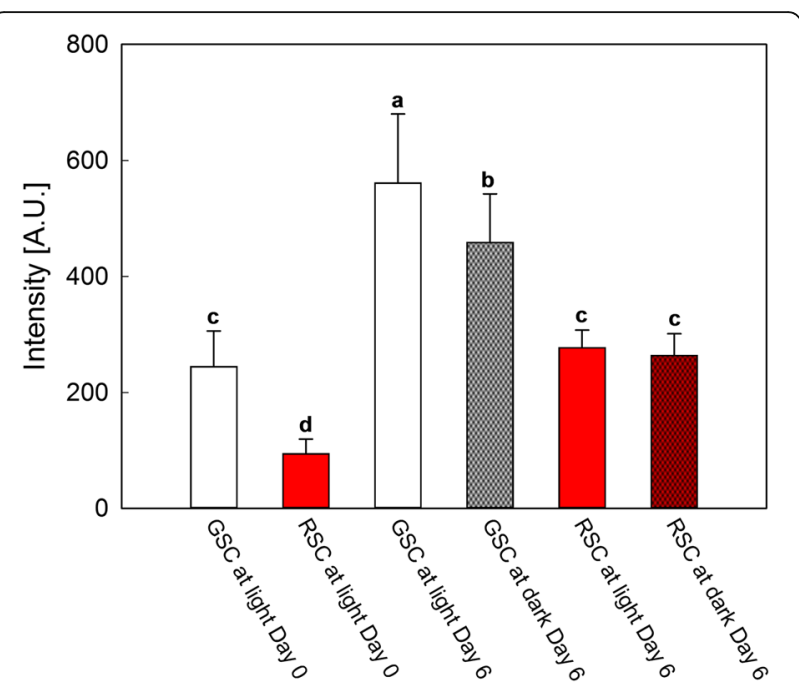

Fig. 4 Cytochrome $c$ release in cytosolic fractions isolated from $V$. vinifera (cv. Limberger) suspension cell cultures. GSC and RSC were grown either under light or dark conditions for 6 days. Samples were obtained at day 0 and 6 , respectively, for the analysis of cytochrome $c$ release. The densitometric analysis of cross-reactivity signals were detected after Western blot of cytosolic proteins isolated from cell cultures, incubated with anti-cytochrome $c$ primary antibody. Bars are means \pm S.D. of at least three independent experiments. Different letters indicate significant difference $(P \leq 0.05)$, evaluated by ANOVA test

\section{Reactive oxygen species (ROS) generation in suspension} cell cultures

Since at day 0 GSC and RSC exhibited comparable levels of cell death, it was interesting to assess if the level of ROS production was different in the two systems. Both cell cultures were incubated with the fluorescent probe $\mathrm{H}_{2}$ DCFDA, to monitor the time-course of ROS production (Fig. 6). Panel a shows that GSC generated a significant higher amount of ROS in comparison to RSC, but this ROS overproduction did not induce appreciable differences in cell death after 105 min (inset Panel a). On the contrary, when cells were treated with the free radical generator ABAP, GSC exhibited a dramatic increase of ROS production (Panel b), paralleled by a strong increase of cell death (inset Panel b), which was not observed in RSC.

\section{Discussion}

Flavonoids play several and relevant physiological roles. First, they act as antioxidants, preventing cell death by delaying/inhibiting the activation of genes related to PCD. However, flavonoids need to be constantly reduced in order to function as antioxidants. This could be achieved only by an efficient reducing system, such as that of ascorbate and reduced glutathione, which are supplied by photosynthesis. Second, flavonoids may cause mild uncoupling of the mitochondrial oxidative phosphorylation, 


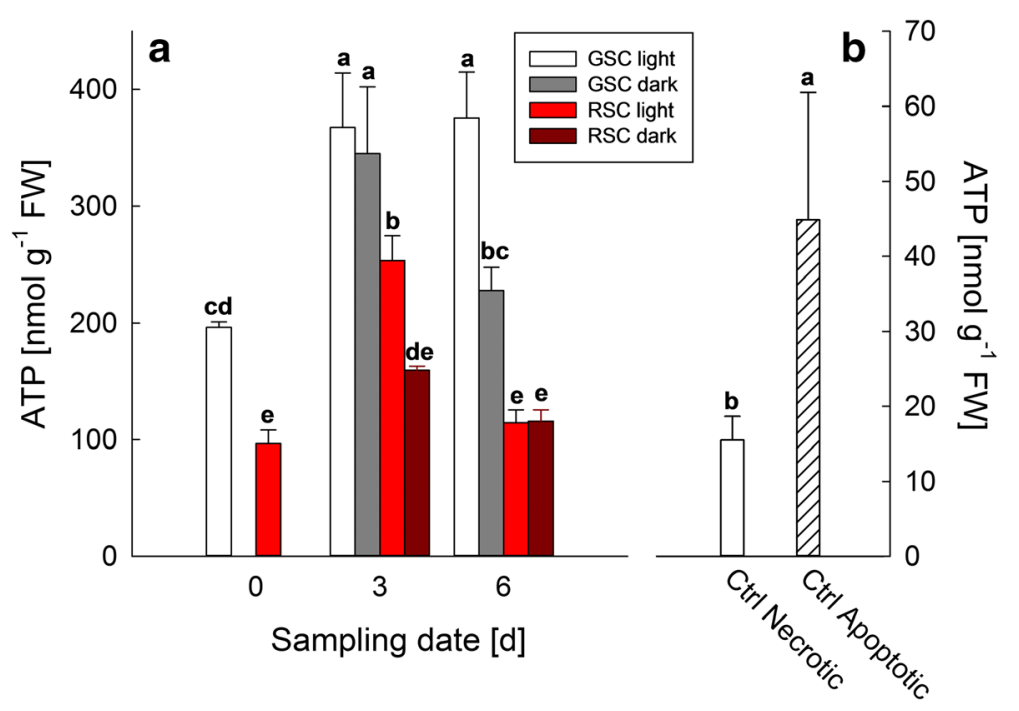

Fig. 5 ATP content in V. vinifera (cv. Limberger) suspension cell cultures. GSC and RSC were grown under light or dark conditions for 6 days, and sampled at day 0, 3 and 6, respectively (Panel a). Necrotic- and apoptotic-like samples, used as positive controls, were obtained on GSC at day 0 , after incubation at $80{ }^{\circ} \mathrm{C}$ for 10 min or with $10 \%(\mathrm{v} / \mathrm{V})$ ethanol for $24 \mathrm{~h}$, respectively (Panel b). Bars are means \pm S.D. of at least three independent experiments. Different letters indicate significant difference $(P \leq 0.05)$, evaluated by ANOVA test

inducing a higher electron flux through the respiratory chain and decrease of transmembrane potential, thus preventing ROS generation by mitochondria [34].

In the present work, the effect of darkness and flavonoids in senescence was assessed by utilizing two grapevine cell cultures obtained from the same callus, one with a high (RSC) and the other with a low (GSC) content of these secondary metabolites (Fig. 1). The starting material grown on solid medium was prone to senescence due to nutrient starvation, whereas the onset of pigmentation observed on the surface of callus was mainly caused by an excess of light on these cells. When sub-cultured in liquid medium, their difference in secondary metabolites at day 0 was, nevertheless, associated to a similar level of cell death. Since GSC and RSC possessed the same genotype, as they were originated by the same callus, they did not genetically differ between each other, except for a stimulated flavonoid biosynthesis pathway and for a different capacity of scavenging ROS overproduction (Fig. 6, Panel b).

The level of cell death in GSC and RSC was low at the beginning of subculture (day 0 ) and substantially comparable, but after 3 days in liquid medium, dark conditions strongly stimulated cell death in both cell cultures (Fig. 2). Such a behaviour is in agreement with previous results $[35,36]$, demonstrating that darkness is an inducing factor of cell death. This effect was more evident at day 3 rather than at day 6 (Fig. 2). The presence of flavonoids decreased this effect in both dark- and light-treated cells.

Buchanan-Wollaston et al. [1] have shown that senescence induced by darkness or starvation exhibits a distinct

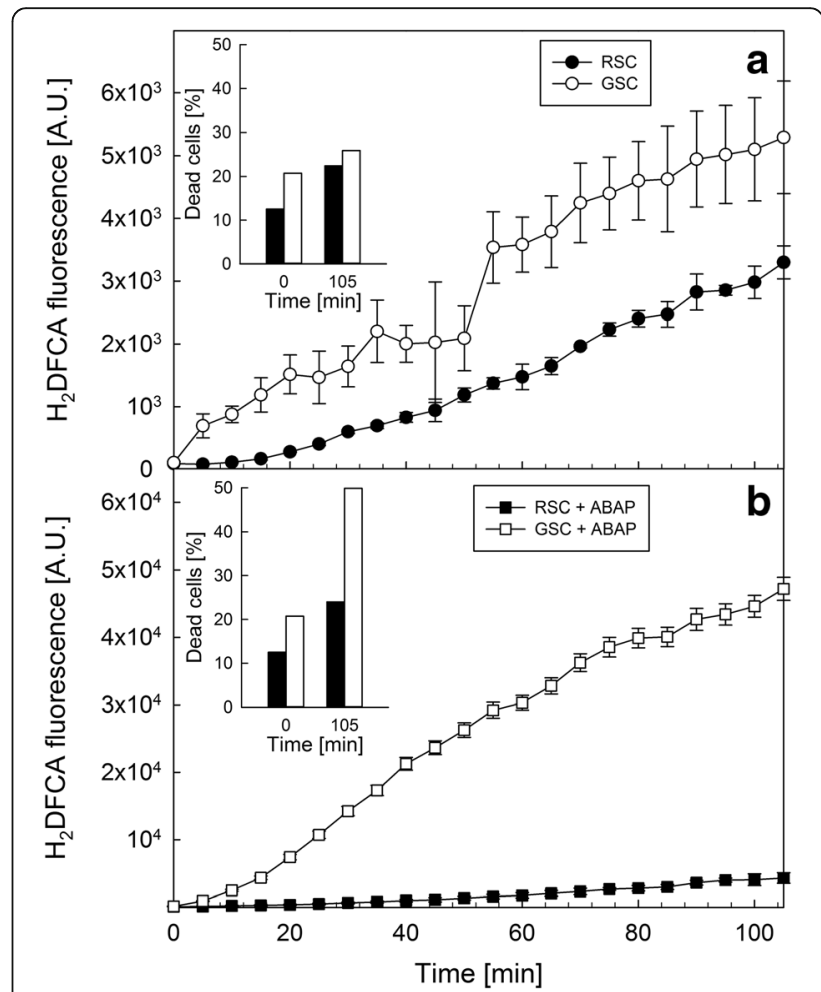

Fig. 6 Reactive oxygen species (ROS) formation in V. vinifera (cV. Limberger) suspension cell cultures. ROS generation was estimated as fluorescence intensity generated by $\mathrm{H}_{2}$ DFCA in GSC and RSC at day 0 . Cell cultures were incubated in the absence (Panel a) or presence (Panel b) of $1 \mathrm{mM}$ ABAP. Insets represent the total amount of dead cells, evaluated by FDA staining at either 0 and $105 \mathrm{~min}$. Bars are means \pm S.D. of at least three independent experiments 
transcriptome pattern, if compared to the developmental program. In addition, darkness increases ROS production [37]. Accordingly, at day 0 (after 23 days of starvation on solid medium), GSC showed higher ROS evolution than RSC (Fig. 6), because flavonoids, acting as antioxidants, decreased ROS production.

After 6 days, apoptosis-like PCD became apparent, as shown by TUNEL assay (Fig. 3) and cytochrome $c$ release (Fig. 4). Apoptosis-like PCD was more pronounced in light-grown GSC than in those grown in the darkness. Flavonoids decreased this type of death, confirming that, in addition to dark-induced cell death, these metabolites specifically protected the cells against PCD. Indeed, a high ATP level, which favours the execution of apoptosis $[38,39]$, was still evident after 6 days in GSC and was compatible with the occurrence of apoptosis-like PCD (Fig. 5, Panel a). The higher content of ATP in GSC, if compared to RSC, can be explained with a more efficient photosynthetic activity in the former cells, which was already evident at day 0 . The difference in ATP content between GSC and RSC was amplified also by light treatment, because only suspension cell cultures grown in light have functional chloroplasts [40]. Darkness lowered ATP in both GSC and RSC, albeit this effect was more pronounced in the RSC after 6 days.

The protecting effect of flavonoids against cell death, particularly after 6 days, could be due to their antioxidant activity $[41,42]$. ROS could be therefore maintained below a critical level to avoid that they become cytotoxic and thus acting as necrosis inducers [43]. This protection could even prevent ROS from behaving as signals to trigger apoptosis-like PCD [44] in RSC mitochondria, where ROS synthesis is known to be lower, if compared to that of chloroplast [45].

It should be stressed that the effect of plastidial ROS has been found to occur downstream of the mitochondrial release of pro-apoptotic factors, but before the caspase activation [46-48]. In GSC grown in the light additional PCD could thus be induced, by overlapping of mitochondrial and chloroplast pathways. The apoptosis-like PCD, occurring mainly in light-grown GSC (Figs. 3 and 4), could also depend on the involvement of chloroplasts [44, 49]. In agreement to this, in Arabidopsis UV light alone induces PCD mediated by caspase-like activities [50]. This could explain the increase in PCD that was observed in light-treated GSC even if mitochondrial pathway was predominant. Conversely, in light- and dark-treated RSC, flavonoids protected from PCD (Figs. 3 and 4), which is a phenomenon particularly evident at day 6 .

\section{Conclusions}

In conclusion, darkness was responsible for triggering mainly necrotic cell death, induced by high ROS production, coupled with an inefficient antioxidant system. It is noteworthy that cells transferred from solid to liquid media had to face a strong oxidative environment. Conversely, PCD was more stimulated in light-grown GSC, since the ROS triggering was not counteracted by flavonoids. The involvement of polyphenolic compounds may be also hypothesized at mitochondrial level, as already suggested in mammals, where such compounds decrease hydrogen peroxide formation by interacting with complex I [34]. Similarly, these secondary metabolites could minimize the oxidative damage caused by plastidial ROS.

\section{Supplementary material}

Additional file 1: Figure S1 was added as supplementary material and shows proliferation rate of $V$. vinifera (cv. Limberger) cell cultures grown on solid medium. Additional file 3: Figure S2, Additional file 4: Figure S3, Additional file 5: Figure S4, Additional file 6: Figure S5 and Additional file 7: Figure $\mathrm{S} 6$ were also added as supplementary materials and show the MS spectra regarding grapevine cell culture alcoholic extracts and reference standards.

Additional file 2: Table S1 was added as supplementary material and shows protein and hexose content of cell cultures at day 0 .

\section{Additional files}

Additional file 1: Figure S1. Proliferation rate of $V$. vinifera (cv. Limberger) cell cultures grown on solid medium. Cell cultures were grown under light for 23 days. Bars represent means \pm S.D. of at least three independent experiments. (TIF $176 \mathrm{~kb}$ )

Additional file 2: Table S1. Senescence hallmarks in GSC and RSC. Measurement of total protein content and hexose concentration in GSC and RSC at day 0, just before liquid culture establishment. (DOCX 13 kb)

Additional file 3: Figure S2. Mass spectra obtained using Multi-stage Mass Spectrometry $\left(\mathrm{MS}^{n}\right)$ for analysis of alcoholic extracts obtained by $V$. vinifera (cv. Limberger) suspension cell cultures. Upper spectrum represents the spectrum obtained from crude extract obtained from RSC grown for 6 days under light. Middle spectrum and lower spectrum represent spectra from two different fractions eluted with $\mathrm{H}_{2} \mathrm{O}$ and methanol from C18 SPE column, respectively. (TIF $47 \mathrm{~kb}$ )

Additional file 4: Figure S3. Structural characterization of malvidinglucoside standard by Mass spectra, using $\mathrm{MS}^{n}$. Upper spectrum shows full spectrum of malvidin-glucoside. Lower spectrum shows spectrum of CID (collision induced dissociation) of the $[\mathrm{M}-\mathrm{H}]^{-}$ion at $\mathrm{m} / \mathrm{z} 491.1$ ion of malvidin-glucoside. (TIF $41 \mathrm{~kb}$ )

Additional file 5: Figure S4. Structural characterization of gallic acid standard by Mass spectra, using MS ${ }^{n}$. Upper spectrum shows full spectrum of gallic acid. Lower spectrum shows spectrum of CID of the $[\mathrm{M}-\mathrm{H}]^{-}$ion at $\mathrm{m} / \mathrm{z} 168.8$ of gallic acid. (TIF $35 \mathrm{~kb}$ )

Additional file 6: Figure S5. Structural characterization of quercetinglucoside standard by Mass spectra, using $\mathrm{MS}^{n}$. Upper spectrum shows full spectrum of quercetin-glucoside. Lower spectrum shows spectrum of $\mathrm{CID}$ of the $[\mathrm{M}-\mathrm{H}]^{-}$ion at $\mathrm{m} / \mathrm{z} 463.1$ of quercetin-glucoside. (TIF $30 \mathrm{~kb}$ )

Additional file 7: Figure S6. Structural characterization of kaempferol standard by Mass spectra, using MS $^{n}$. Upper spectrum shows full spectrum of kaempferol. Lower spectrum shows spectrum of CID of the $[\mathrm{M}-\mathrm{H}]^{-}$ion at $\mathrm{m} / \mathrm{z} 285$ ion of kaempferol. (TIF $32 \mathrm{~kb}$ ) 


\section{Abbreviations}

ABAP: 2,2-azobis(2-methylpropionamide)hydrochloride; CID: Collision induced dissociation; DAPI: 4',6-diamidino-2-phenylindole; FDA: Fluorescein diacetate; GSC: Green suspension cell cultures; H2DCFDA: 2',7'-dichlorodihydrofluorescein diacetate; HR: Hypersensitive reaction; LC-ESI-MS: Liquid chromatography electrospray ionization - mass spectrometry; LSD: Least significant difference; MS $^{\text {n }}$ : Multi-stage mass spectrometry; PBS: Phosphate buffered saline; PCD: Programmed cell death; ROS: Reactive oxygen species; RSC: Red suspension cell cultures; TUNEL assay: In situ detection of DNA fragmentation

\section{Acknowledgements}

We thank Prof. G. Verardo and Dr. A. Gorassini of the University of Udine for their help in the identification of polyphenolic metabolites by means of LC-ESI-MS analysis. We are also very grateful to Dr. V. Repka for kindly supplying callus cultures of grapevine (Vitis vinifera L., Cv. Limberger).

\section{Funding}

This work was supported by the Italian Ministry of Education, University and Research (National Research Program PRIN2010CSJX4F).

\section{Availability of data and materials}

All data supporting our findings are contained within the manuscript.

\section{Authors' contributions}

$A B$ performed the experiments on cell death markers (FDA staining, TUNEL, cytochrome $c$ release and immunoassay), ATP content and ROS production. $\mathrm{He}$ also contributed to write the manuscript and to its critical revision. EP conceived and designed the experiments, acquired the data regarding cell death markers (FDA staining, TUNEL, cytochrome $c$ release and immunoassay). She collaborated to drafting the manuscript and to its critical revision. SP performed the chromatographic analysis of polyphenols and critically revised the manuscript. MZ, CP and VC contributed to the critical revision of the manuscript. AV conceived and designed the research, and co-wrote the manuscript. EB conceived and designed the experiments, performed the statistical data analysis, and co-wrote the manuscript. All authors have read and approved this manuscript.

\section{Competing interests}

The authors declare that they have no competing interest.

\section{Consent for publication}

Not applicable.

\section{Ethics approval and consent to participate}

Not applicable.

\section{Received: 29 April 2016 Accepted: 10 October 2016}

\section{Published online: 26 October 2016}

\section{References}

1. Buchanan-Wollaston V, Page T, Harrison E, Breeze E, Lim PO, Nam HG, Lin JF, Wu SH, Swidzinski J, Ishizaki K, et al. Comparative transcriptome analysis reveals significant differences in gene expression and signalling pathways between developmental and dark/starvation-induced senescence in Arabidopsis. Plant J. 2005;42(4):567-85.

2. Pastori GM, del Rio LA. Natural senescence of pea leaves - An activated oxygen-mediated function for peroxisomes. Plant Physiol. 1997;113(2):411-8.

3. Guo Y, Cai Z, Gan S. Transcriptome of Arabidopsis leaf senescence. Plant Cell Environ. 2004;27(5):521-49.

4. Hoeberichts FA, Woltering EJ. Multiple mediators of plant programmed cell death: interplay of conserved cell death mechanisms and plant-specific regulators. Bioessays. 2003;25(1):47-57.

5. Swidzinski JA, Sweetlove LJ, Leaver CJ. A custom microarray analysis of gene expression during programmed cell death in Arabidopsis thaliana. Plant J. 2002;30(4):431-46.

6. Pennell RI, Lamb C. Programmed cell death in plants. Plant Cell. 1997;9(7): 1157-68.

7. Curtin C, Zhang W, Franco C. Manipulating anthocyanin composition in Vitis vinifera suspension cultures by elicitation with jasmonic acid and light irradiation. Biotechnol Lett. 2003;25(14):1131-5.
8. Batra P, Sharma AK. Anti-cancer potential of flavonoids: recent trends and future perspectives. 3 Biotech. 2013;3(6):439-59.

9. Ceoldo S, Levi M, Marconi AM, Baldan G, Giarola M, Guzzo F. Image analysis and in vivo imaging as tools for investigation of productivity dynamics in anthocyanin-producing cell cultures of Daucus carota. New Phytol. 2005; 166(1):339-52.

10. Lord CEN, Wertman JN, Lane S, Gunawardena AHLAN: Do mitochondria play a role in remodelling lace plant leaves during programmed cell death? BMC Plant Biol. 2011, 11:102-119. Erratum in BMC Plant Biol. 2013; 2013:2058

11. Lord CEN, Dauphinee AN, Watts RL, Gunawardena AHLAN. Unveiling Interactions among Mitochondria, Caspase-Like Proteases, and the Actin Cytoskeleton during Plant Programmed Cell Death (PCD). PloS One. 2013:8(3):e57110.

12. Gould KS, McKelvie J, Markham KR. Do anthocyanins function as antioxidants in leaves? Imaging of $\mathrm{H}(2) \mathrm{O}(2)$ in red and green leaves after mechanical injury. Plant Cell Environ. 2002;25(10):1261-9.

13. Zhang Y, Butelli E, De Stefano R, Schoonbeek HJ, Magusin A, Pagliarani C, Wellner N, Hill L, Orzaez D, Granell A, et al. Anthocyanins Double the Shelf Life of Tomatoes by Delaying Overripening and Reducing Susceptibility to Gray Mold. Curr Biol. 2013;23(12):1094-100.

14. Dai J, Mumper RJ. Plant Phenolics: Extraction, Analysis and Their Antioxidant and Anticancer Properties. Molecules. 2010;15(10):7313-52.

15. Wang LS, Stoner GD. Anthocyanins and their role in cancer prevention. Cancer Lett. 2008;269(2):281-90.

16. Kampa M, Hatzoglou A, Notas G, Damianaki A, Bakogeorgou E, Gemetzi C, Kouroumalis E, Martin PM, Castanas E. Wine antioxidant polyphenols inhibit the proliferation of human prostate cancer cell lines. Nutr Cancer. 2000; 37(2):223-33.

17. Seeram NP, Adams LS, Zhang YJ, Lee R, Sand D, Scheuller HS, Heber D. Blackberry, black raspberry, blueberry, cranberry, red raspberry, and strawberry extracts inhibit growth and stimulate apoptosis of human cancer cells in vitro. J Agric Food Chem. 2006:54(25):9329-39.

18. Damianaki A, Bakogeorgou E, Kampa M, Notas G, Hatzoglou A, Panagiotou S, Gemetzi C, Kouroumalis E, Martin PM, Castanas E. Potent inhibitory action of red wine polyphenols on human breast cancer cells. J Cell Biochem. 2000;78(3):429-41.

19. Rabah IO, Hou DX, Komine SI, Fujii M. Potential chemopreventive properties of extract from baked sweet potato (Ipomoea batatas Lam. cV. Koganesengan). J Agric Food Chem. 2004;52(23):7152-7.

20. Tavares S, Vesentini D, Fernandes JC, Ferreira RB, Laureano O, Ricardo-Da-Silva JM, Amancio S. Vitis vinifera secondary metabolism as affected by sulfate depletion: Diagnosis through phenylpropanoid pathway genes and metabolites. Plant Physiol Biochem. 2013;66:118-26.

21. Winkel-Shirley B. Biosynthesis of flavonoids and effects of stress. Curr Opin Plant Biol. 2002;5(3):218-23.

22. Calderon AA, Zapata JM, Pedreno MA, Munoz R, Barcelo AR. Levels of 4Hydroxystilbene-Oxidizing Isoperoxidases Related to Constitutive Disease Resistance in Invitro-Cultured Grapevine. Plant Cell Tissue Organ Cult. 1992;29(2):63-70.

23. Repka V. Hydrogen peroxide generated via the octadecanoid pathway is neither necessary nor sufficient for methyl jasmonate-induced hypersensitive cell death in woody plants. Biol Plant. 2002;45(1):105-15.

24. Repka V, Fischerova I, Silharova K. Methyl jasmonate is a potent elicitor of multiple defense responses in grapevine leaves and cell-suspension cultures. Biol Plant. 2004;48(2):273-83.

25. Repka V, Kubikova J, Fischerova I. Immunodetection of PR-1-like proteins in grapevine leaves infected with Oidium tuckeri and in elicited suspension cell cultures. Vitis. 2000;39(3):123-7.

26. Rolland F, Moore B, Sheen J. Sugar sensing and signaling in plants. Plant Cell. 2002;14:S185-205.

27. Wingler A, Purdy S, MacLean JA, Pourtau N. The role of sugars in integrating environmental signals during the regulation of leaf senescence. J Exp Bot. 2006:57(2):391-9.

28. Bradford M. A rapid and sensitive method for the quantitation of microgram quantities of protein utilizing the principle of protein-dye binding. Anal Biochem. 1976;72:248-54.

29. Petrussa E, Bertolini A, Casolo V, Krajnakova J, Macri F, Vianello A. Mitochondrial bioenergetics linked to the manifestation of programmed cell death during somatic embryogenesis of Abies alba. Planta. 2009;231(1):93-107.

30. McCabe PF, Leaver CJ. Programmed cell death in cell cultures. Plant Mol Biol. 2000;44(3):359-68 
31. Ledoux Q, Veys P, Van Cutsem P, Mauro S, Lucaccioni F, Marko I. Validation of the boronate sensor ContPY1 as a specific probe for fluorescent detection of hydrogen peroxide in plants. Plant Signal Behav. 2013;8(11):e26827.

32. Santos A, Miquel A, Tomaz L, Malhó R, Maycock C, Vaz Patto M, Fevereiro P, Oliva A. The impact of CdSe/ZnS Quantum Dots in cells of Medicago sativa in suspension culture. J Nanobiotechnology. 2010;8(24):1-14.

33. Hogg BV, Kacprzyk J, Molony EM, O'Reilly C, Gallagher TF, Gallois P, McCabe PF. An in vivo root hair assay for determining rates of apoptotic-like programmed cell death in plants. Plant Methods. 2011;7:45-54.

34. Lagoa R, Graziani I, Lopez-Sanchez C, Garcia-Martinez V, Gutierrez-Merino C. Complex I and cytochrome $\mathrm{c}$ are molecular targets of flavonoids that inhibit hydrogen peroxide production by mitochondria. Biochim Biophys Acta. 2011;1807(12):1562-72.

35. Hajouj T, Michelis R, Gepstein S. Cloning and characterization of a receptorlike protein kinase gene associated with senescence. Plant Physiol. 2000; 124(3):1305-14.

36. Lin JF, Wu SH. Molecular events in senescing Arabidopsis leaves. Plant J. 2004;39(4):612-28.

37. Rosenvasser S, Mayak S, Friedman H. Increase in reactive oxygen species (ROS) and in senescence-associated gene transcript (SAG) levels during dark-induced senescence of Pelargonium cuttings, and the effect of gibberellic acid. Plant Sci. 2006;170(4):873-9.

38. Kroemer G, Dallaporta B, Resche-Rigon M. The mitochondrial death/life regulator in apoptosis and necrosis. Annu Rev Physiol. 1998;60:619-42.

39. Desagher S, Martinou JC. Mitochondria as the central control point of apoptosis. Trends Cell Biol. 2000;10(9):369-77.

40. Doyle SM, Diamond M, McCabe PF. Chloroplast and reactive oxygen species involvement in apoptotic-like programmed cell death in Arabidopsis suspension cultures. J Exp Bot. 2010;61(2):473-82.

41. Hernandez I, Alegre L, Van Breusegem F, Munne-Bosch S. How relevant are flavonoids as antioxidants in plants? Trends Plant Sci. 2009;14(3):125-32.

42. Spatafora C, Barbagallo E, Amico V, Tringali C. Grape stems from Sicilian Vitis vinifera cultivars as a source of polyphenol-enriched fractions with enhanced antioxidant activity. LWT- Food Sci Technol. 2013;54(2):542-8.

43. Munne-Bosch S, Alegre L. Die and let live: leaf senescence contributes to plant survival under drought stress. Funct Plant Biol. 2004;31(3):203-16.

44. Gadjev I, Stone JM, Gechev TS. Programmed Cell Death in Plants: New Insights into Redox Regulation and the Role of Hydrogen Peroxide. Int Rev Cell Mol Biol. 2008;270:87-144.

45. Foyer $\mathrm{CH}$, Noctor $\mathrm{G}$. Redox sensing and signalling associated with reactive oxygen in chloroplasts, peroxisomes and mitochondria. Physiol Plant. 2003;119(3):355-64.

46. Rosenwasser S, Rot I, Sollner E, Meyer AJ, Smith Y, Leviatan N, Fluhr R, Friedman H. Organelles Contribute Differentially to Reactive Oxygen Species-Related Events during Extended Darkness. Plant Physiol. 2011;156(1): 185-201.

47. Wang HJ, Zhu XN, Li H, Cui J, Liu C, Chen X, Zhang W. Induction of Caspase-3-like activity in Rice following release of cytochrome-f from the chloroplast and subsequent interaction with the Ubiquitin-Proteasome System. Sci Rep. 2014:4:5989-99.

48. Kim C, Meskauskiene R, Zhang SR, Lee KP, Ashok ML, Blajecka K, Herrfurth C, Feussner I, Apel K. Chloroplasts of Arabidopsis Are the Source and a Primary Target of a Plant-Specific Programmed Cell Death Signaling Pathway. Plant Cell. 2012;24(7):3026-39.

49. Petrov V, Hille J, Mueller-Roeber B, Gechev TS. ROS-mediated abiotic stress-induced programmed cell death in plants. Front Plant Sci. 2015;6:69-96.

50. Danon A, Rotari VI, Gordon A, Mailhac N, Gallois P. Ultraviolet-C overexposure induces programmed cell death in Arabidopsis, which is mediated by caspase-like activities and which can be suppressed by caspase inhibitors, p35 and Defender against Apoptotic Death. J Biol Chem. 2004;279(1):779-87.

\section{Submit your next manuscript to BioMed Central and we will help you at every step:}

- We accept pre-submission inquiries

- Our selector tool helps you to find the most relevant journal

- We provide round the clock customer support

- Convenient online submission

- Thorough peer review

- Inclusion in PubMed and all major indexing services

- Maximum visibility for your research

Submit your manuscript at www.biomedcentral.com/submit
Biomed Central 